\title{
Retraction
}

\section{Retracted: Influence of DPYD Genetic Polymorphisms on 5- Fluorouracil Toxicities in Patients with Colorectal Cancer: A Meta-Analysis}

\author{
Gastroenterology Research and Practice \\ Correspondence should be addressed to Gastroenterology Research and Practice; grp@hindawi.com \\ Received 10 September 2020; Accepted 10 September 2020; Published 21 November 2020 \\ Copyright (C) 2020 Gastroenterology Research and Practice. This is an open access article distributed under the Creative Commons \\ Attribution License, which permits unrestricted use, distribution, and reproduction in any medium, provided the original work is \\ properly cited.
}

Gastroenterology Research and Practice has retracted the article titled "Influence of DPYD Genetic Polymorphisms on 5-Fluorouracil Toxicities in Patients with Colorectal Cancer: A Meta-Analysis" [1]. This article is one of a series of very similar meta-analyses written by different authors that were published in 2014 and 2015, featuring characteristic phrases [2]. Overlaps of wording with these articles are concentrated in the Materials and Methods and Results sections, and a paragraph in the Discussion.

Two similar meta-analyses were not discussed $[3,4]$. The authors could not be contacted.

\section{References}

[1] Q. Li, Y. Liu, H.-M. Zhang et al., "Influence of DPYD Genetic Polymorphisms on 5-Fluorouracil Toxicities in Patients with Colorectal Cancer: A Meta-Analysis," Gastroenterology Research and Practice, vol. 2014, Article ID 827989, 11 pages, 2014.

[2] G. Filion, "A flurry of copycats on PubMed," The Grand Locus, 2014, http://blog.thegrandlocus.com/2014/10/a-flurry-ofcopycats-on-pubmed. View at Google Scholar.

[3] S. Terrazzino, S. Cargnin, M. Del Re, R. Danesi, P. L. Canonico, and A. A. Genazzani, "DPYDIVS14+1G>a and $2846 \mathrm{~A}>\mathrm{T}$ genotyping for the prediction of severe fluoropyrimidinerelated toxicity: a meta-analysis," Pharmacogenomics, vol. 14, no. 11, pp. 1255-1272, 2013.

[4] D. Rosmarin, C. Palles, D. Church et al., "Genetic markers of toxicity from capecitabine and other fluorouracil-based regimens: investigation in the QUASAR2 study, systematic review, and meta-analysis," Journal of Clinical Oncology, vol. 32, no. 10, pp. 1031-1039, 2014. 